\title{
The difference between the cycloplegic and noncycloplegic refractive error may be an indicator for the myopia progression in myopic children
}

\author{
(스cattin İlker Kocamış ${ }^{1}$, @İbrahim Özdemir ${ }^{2}$ \\ ${ }^{1}$ Yenikent State Hospital, Ophthalmology Department, Sakarya, Turkey \\ ${ }^{2}$ Dünyagöz Hospital, Ophthalmology Department, Sakarya, Turkey
}

Cite this article as: Kocamış Sİ, Özdemir İ. The difference between the cycloplegic and noncycloplegic refractive error may be an indicator for the myopia progression in myopic children. J Health Sci Med 2022; 5(1): 287-290.

\begin{abstract}
Aim: We aimed to evaluate the relationship between the subjective and objective refractive error measurement difference and myopia progression in this study.

Material and Method: Children between 6-18 year-old at the beginning of the follow-up period having myopia and who were followed up regularly every six months and for a total of at least 36 months were included in the study. All children underwent a detailed ophthalmologic examination. An autorefractor (TOPCON KR1/RM1, Topcon, Oakland, New Jersey), was used to evaluate the refractive error. Those with a refractive error difference of less than $0.50 \mathrm{D}$ (spherical equivalent) before and after cycloplegia were included in group 1. Those with a refractive error difference of higher than $0.50 \mathrm{D}$ were included in group 2. Myopic progression of the groups was compared.

Results: This study comprised 44 patients (male, 23; female, 21) in group 1 and 42 patients (male, 22; female, 20) in group 2. The age range and mean age $\pm \mathrm{SD}$ of patients in group 1 were 6-17 years and $11.4 \pm 3.0$ years, respectively, whereas that of patients in group 2 was 6-17 years and 12.6 \pm 3.3 years, respectively. Both groups were followed for similar periods $(p=0.141)$. It was 37.5 \pm 2.4 (range 36-48) months in group 1 and 36.8 \pm 1.6 (range 36-42) months in group 2. The range and mean of the cycloplegic refractive error at the beginning of the following period in group 1 were $-2.37 \pm 1.15 \mathrm{D}$, and $-1.75 \pm 0.99 \mathrm{D}$ in group 2 respectively $(p=0.010)$. At the end of the following period, the mean cycloplegic refractive error were $-2.73 \pm 1.11 \mathrm{D}$ in group 1 , and $-3,33 \pm 0.91 \mathrm{D}$ in group 2 respectively $(\mathrm{p}=0.008)$. During follow-up, the change in cycloplegic refractive error was $0.36 \pm 0.16$ $\mathrm{D}$ in group 1 , and $1.57 \pm 0.46 \mathrm{D}$ in group 2 . It was significantly lower in group 1 than group $2(\mathrm{p}<0.0001)$.

Conclusion: We demonstrated that myopic children having high baseline difference between the objective and subjective spheric equivalent measurements had more myopia progression.
\end{abstract}

Keywords: Accommodation, cycloplegic refraction, myopia progression

\section{INTRODUCTION}

Myopia is one of the main causes of childhood blindness (1). Research on myopia is gaining more attention as it has become a worldwide public health issue. Although mild to moderate myopia is usually innocuous, high myopia may lead to significant ocular morbidities like cataract, retinal detachment, macular hole, and glaucoma (2). Therefore, understanding the pathophysiology of myopia progression is a significant issue. Risk factors for myopia progression are still unclear. Nevertheless genetics, ethnicity, age and near work are the mostly emphasized factors in myopia progression (3-6).
Excessive accommodation and ciliary muscle spasms due to the sustained near work lead to the alteration of the lens and myopic defocus on the retina subsequently. In the Tehran eye study, it was found that the difference between the objective and subjective refractive error was up to 0.71 Diopter (D) in 5-10 years children (7). According to the Chinese Medical Association of Ophthalmology, accommodative factors are taking part in $\% 60$ of the myopic school aged children (8). Therefore, accommodative incongruences might be a research issue for myopia progression. 
Cycloplegic refraction should be employed especially in children while detecting the exact refractive error. Cycloplegia eliminates the accommodation and prevents the overestimation of myopia (9). Pseudo myopia is defined as high myopia due to the accommodative spasm which caused by the prolonged near work. After cycloplegia, myopia is disappeared in pseudo myopia. Despite that, myopia still exists and is not decreased more than $0.50 \mathrm{D}$ in true myopia (8). In our clinic, we observe patients with more than $0.50 \mathrm{D}$ myopia decrease and still having myopia after cycloplegic refraction. Accordingly, we aimed to evaluate the relationship between the subjective and objective refractive error measurement difference (SOD) and myopia progression in this study.

\section{MATERIAL AND METHOD}

This study was planned retrospectively to review patients who came to the ophthalmology department with the complaint of farsightedness or diagnosis of myopia between December 1, 2016 and to March 30, 2021. This study was approved by the Ethics Committee of the Sakarya University Medical School (Date: 25.10.2021, Decision No:74730), and all procedures were performed adhered to the ethical rules and principals of the Helsinki Declaration.

Children between 6-18 year-old at the beginning of the follow-up period having myopia and who were followed up regularly every six months and for a total of at least 36 months were included in the study. The exclusion criteria were as follows: strabismus, best- corrected visual acuity $<10 / 10$, astigmatism $>1.00 \mathrm{D}$ in either eye, anisometropia of $>1.0 \mathrm{D}$ between the two eyes, any ocular disorders which may contribute to refractive error change such as cataract and keratoconus, and the usage of any methods to prevent myopia progression.

All children underwent a detailed ophthalmologic examination. Visual acuity with and without correction was tested using Snellen chart. The children were examined monocularly (right eye followed by left eye). A cover test was used to check for the presence of strabismus. For each child, a drop of topical anesthetic (ALCAINE; Alcon Laboratories, TX, USA), and then two drops of $1 \%$ cyclopentolate (SIKLOPLEJIN; Abdi Ibrahim, Ist, Turkey) were applied at five-minute intervals. Thirty minutes after the last drop, a third drop of cyclopentolate was administered if the pupillary light reflex was still present. An autorefractor (TOPCON KR1/RM1, Topcon, Oakland, New Jersey), was used to evaluate the cycloplegic refractive error.

Those with a refractive error difference of less than 0.50 $\mathrm{D}$ (spherical equivalent) before and after cycloplegia were included in group 1 . Those with a refractive error difference of higher than $0.50 \mathrm{D}$ were included in group 2. Myopic progression of the groups was compared.
Data were statistically analyzed using the statistical package for social sciences package v.25.0 (SPSS Inc., Chicago, IL, USA). The Shapiro-Wilk test was used to assess the normal distribution and Levene's test was used to assess variance homogeneity. Independent Sample T Test, Paired Sample T Test and Chi Square Test were also used to evaluate the significant differences between the groups. The value of statistical significance was set at $\mathrm{P}$ 0.05

\section{RESULTS}

This study comprised 44 patients (male, 23; female, 21) in group 1 and 42 patients (male, 22; female, 20) in group 2. The mean age $\pm \mathrm{SD}$ of patients in group 1 was $11.4 \pm 3.0$ years (range 6-17 years), whereas that of patients in group 2 was $12.6 \pm 3.3$ years (range $6-17$ years) $(p=0.069)$ $(\mathrm{p}=0.069)$. Both groups were followed for similar periods $(\mathrm{p}=0.141)$. It was $37.5 \pm 2.4$ (range 36-48) months in group 1 and $36.8 \pm 1.6$ (range 36-42) months in group 2 (Table 1).

The range and mean of the cycloplegic refractive error at the beginning of the following period (T0) in group 1 were $-2.37 \pm 1.15 \mathrm{D}$, and $-1.75 \pm 0.99 \mathrm{D}$ in group 2 respectively $(p=0.010)$. At the end of the following period (T1), the mean cycloplegic refractive error were $-2.73 \pm 1.11 \mathrm{D}$ in group 1 , and $-3,33 \pm 0.91 \mathrm{D}$ in group 2 respectively $(\mathrm{p}=0.008)$. During follow-up, the change in cycloplegic refractive error was $0.36 \pm 0.16 \mathrm{D}$ in group 1 , and $1.57 \pm 0.46 \mathrm{D}$ in group 2 . It was significantly lower in group 1 than group $2(\mathrm{p}<0.0001)$ (Table 1$)$.

\begin{tabular}{|c|c|c|c|}
\hline & $\begin{array}{c}\text { Group } 1 \\
\mathrm{n}=44\end{array}$ & $\begin{array}{c}\text { Group } 2 \\
n=41\end{array}$ & $P$ value \\
\hline Sex F/M & $23 / 21$ & $22 / 20$ & 0.992 \\
\hline Age, year & $11.4 \pm 3.0$ & $12.6 \pm 3.3$ & 0.069 \\
\hline Period, month & $37.5 \pm 2.4$ & $36.8 \pm 1.6$ & 0.141 \\
\hline T0, D & $-2.37 \pm 1.15$ & $-1.75 \pm 0.99$ & 0.010 \\
\hline $\mathrm{T} 1, \mathrm{D}$ & $-2.73 \pm 1.11$ & $-3,33 \pm 0.91$ & 0.008 \\
\hline$\Delta \mathrm{T}, \mathrm{D}$ & $0.36 \pm 0.16$ & $1.57 \pm 0.46$ & $<0.0001$ \\
\hline \multicolumn{4}{|c|}{$\begin{array}{l}\text { D: Diopter, F: Female M: Male, T0: the cycloplegic refractive error at the beginning } \\
\text { of the following period, T1: the cycloplegic refractive error at the end of the following } \\
\text { period, } \Delta \mathrm{T} \text { : the change in cycloplegic refractive error }\end{array}$} \\
\hline
\end{tabular}

\section{DISCUSSION}

In this study, we found that myopic children having greater amounts of SOD initially were more prone to myopia progression. This finding is also in agreement with the outcome of a research derived from the Beijing Myopia Progression Study (10). This study enrolled two hundred and nineteen children aged 6-17 with three years follow up time. It was stated that baseline SOD was correlated with the myopia progression but not associated with onset of myopia. We think that the 
result of our study is important regarding that it can be employed as a useful method to determine the specific patient population that needs treatment in order to prevent myopia progression.

The possible relationship between the accommodation and myopia has been extensively discussed for a long time. In animal models, it was demonstrated that administration of minus lenses provoked the elongation of the eye and myopia $(11,12)$. Based on these studies, it was claimed that insufficient accommodation response to the accommodative stimuli, lag of accommodation, may lead to the hyperopic blur on the retina and cause axial elongation eventually $(13,14)$. Thus, undercorrection of myopia was suggested as a solution to halt the progression. However, it was claimed that undercorrection had no effect on slowing the progression (15). Moreover, some studies showed that undercorrected children had more myopia progression than the fully corrected children $(16,17)$. Undercorrection induces myopic defocus like excessive accommodation does. Therefore, we think that myopic defocus due to excessive accommodation may lead to the myopic progression in our study. Moreover, Jin et al's (18) recent study showed that SOD is negatively correlated with the accommodation lag. Based on this study, we can state that myopia progression in our study cohort is not associated with the high accommodation lag. Additionally, in Hussaindeen et al. (19) study, it was demonstrated that in myopic eyes having more than $1 \mathrm{D}$ difference in SOD, all of the accommodation factors other than the accommodation amplitude were not significantly different than the control group.

There are numerous works indicating the possible relation between the near work and the myopia progression, thus supporting the potential role of accommodation in myopia progression $(20,21)$. Nevertheless, attempts to modify the accommodation and slowing the myopia progression with undercorrection, bifocal and multifocal spectacles seem to have mild and clinically nonsignificant outcomes (22). In a clinical study, bifocal soft contact lenses and spherical soft contact lenses were employed in the contralateral eyes of the myopic children simultaneously. After a certain period, the lenses were switched and used for the same amount of time. It was demonstrated that bifocal contact lenses slowed myopia progression much more compared to soft spherical lenses even after the switching (23). This study indicated that peripheral myopic defocus might be the notable factor rather than the accommodation in myopia progression as the accommodation was modified evenly in both eyes. Also, it was shown that despite the intensity of the near work increases with the age, the myopia does not progress (24).
It was proposed that accommodation errors might be a consequence of myopia rather than the reason of it (25). The amount of SOD was gradually decreased in high SOD group after the full correction with spectacles throughout the follow up in the Lin et al. (10) aforementioned study. Therefore, we can assert that excessive accommodation might be induced due to the uncorrection of myopia during certain amount of time. However, in our study, we do not exactly know since when they had been myopic before the treatment. Another significant agent administered in myopia progression is atropine. Based on the animal studies, it is thought that atropine does not slow the myopia via reducing the accommodation (26). However, the exact mechanism is still unknown. We think that adopting the animal models exactly into human pathophysiology may cause bias. We cannot fully exclude the role of accommodation mechanism according to the fact that rebound effect is seen after the cessation of the atropine (27). Accordingly, we suggest the administration of atropine to the myopic patients having initial SOD more than $0.50 \mathrm{D}$ and progressive myopia in order to benefit from both cycloplegic effect and neuromodulator effect of the atropine to halt the myopia progression.

Our study has some drawbacks mostly arises from the nature of retrospective design. Firstly, our sample size was relatively small. Secondly, axial length measurements were absent. However, initial cycloplegic refractive error was higher in low SOD group than the high SOD group. It was suggested that higher initial myopic error would lead to more myopia progression (28). Therefore, the results in this study reinforce our hypothesis. Nonetheless, comparing the differences in axial lengths in both groups would contribute to myopia progression evaluation. Thirdly, no data about the near work activities were present. On the other hand, all the children were school aged children. Lastly, it is known that higher order aberrations can have effect on the measured SOD (29). Corneal aberrations were not measured in our study cohort. However, it was presented that there was no statistically significant difference in aberrations between the myopic eyes having high SOD and having normal SOD (18).

\section{CONCLUSION}

In conclusion, we demonstrated that myopic children having high baseline difference between the objective and subjective spheric equivalent measurements had more myopia progression. Further prospective studies with larger sample sizes are needed to investigate whether this difference is a consequence of untreated myopic error for a certain amount of time and its possible relation with the myopia progression. 


\section{ETHICAL DECLERATIONS}

Ethics Committee Approval: The study was initiated with the approval of the Sakarya University Medical School Ethics Committee (Date: 25.10.2021, Decision No:74730).

Informed Consent: Because the study was designed retrospectively, no written informed consent form was obtained from patients.

Referee Evaluation Process: Externally peer reviewed.

Conflict of Interest Statement: The authors have no conflicts of interest to declare.

Financial Disclosure: The authors declared that this study has received no financial support.

Author Contributions: All of the authors declare that they have all participated in the design, execution, and analysis of the paper, and that they have approved the final version.

\section{REFERENCES}

1. Vitale S, Sperduto RD, Ferris FL, $3^{\text {rd }}$ Increased prevalence of myopia in the United States between 1971-1972 and 1999-2004. Arch Ophthalmol 2009; 127: 1632-9.

2. Saw SM, Gazzard G, Shih-Yen EC, Chua WH. Myopia and associated pathological complications. Ophthalmic Physiol Opt 2005; 25: 381-91.

3. Hammond CJ, Snieder H, Gilbert CE, Spector TD. Genes and environment in refractive error: the twin eye study. Invest Ophthalmol Vis Sci 2001; 42: 1232-6.

4. Fan DSP, Lam DSC, Lam RF, et al. Prevalence, incidence, and progression of myopia of school children in Hong Kong. Invest Ophthalmol Vis Sci 2004; 45: 1071-5.

5. Zadnik K, Sinnott LT, Cotter SA, et al. Prediction of juvenileonset myopia. JAMA Ophthalmol 2015; 133: 683-9.

6. Polling JR, Verhoeven VJ, Tideman JW, Klaver CC. Duke-Elder's views on prognosis, prophylaxis, and treatment of myopia: way ahead of his time. Strabismus 2016; 24: 40-3.

7. Fotouhi A, Morgan IG, Iribarren R, Khabazkhoob M, Hashemi $\mathrm{H}$. Validity of noncycloplegic refraction in the assessment of refractive errors: the Tehran Eye Study. Acta Ophthalmol 2012; 90: 380-6.

8. Chinese Medical Association of Ophthalmology DoR. Definition and classic criterion for distinguishing between true myopia and pseudo-myopia. Chinese J Ophthalmol 1986; 22: 184-5.

9. Morgan IG, Iribarren R, Fotouhi A, Grzybowski A. Cycloplegic refraction is the gold standard for epidemiological studies. Acta Ophthalmol 2015; 93: 581-5.

10. Lin Z, Vasudevan B, Ciuffreda KJ, et al. The difference between cycloplegic and noncycloplegic autorefraction and its association with progression of refractive error in Beijing urban children. Ophthalmic Physiol Opt 2017; 37: 489-97.

11. Howlett MH, McFadden SA. Form-deprivation myopia in the guinea pig (Cavia porcellus). Vision Res 2006; 46: 267-83.

12. Tkatchenko TV, Shen Y, Tkatchenko AV. Mouse experimental myopia has features of primate myopia. Invest Ophthalmol Vis Sci 2010; 51: 1297-303.

13. Seidemann A, Schaeffel F. An evaluation of the lag of accommodation using photorefraction. Vision Res 2003; 43: 419 30 .
14. Gwiazda JE, Hyman L, Norton TT, et al. Accommodation and related risk factors associated with myopia progression and their interaction with treatment in COMET children. Invest Ophthalmol Vis Sci 2004; 45: 2143-51.

15. Koomson NY, Amedo AO, Opoku-Baah C, Ampeh PB, Ankamah E, Bonsu K. Relationship between reduced accommodative lag and myopia progression. Optom Vis Sci 2016; 93: 683-91.

16. Chung K, Mohidin N, O'Leary DJ. Undercorrection of myopia enhances rather than inhibits myopia progression. Vision Res 2002; 42: 2555-9.

17. Adler D, Millodot M. The possible effect of undercorrection on myopic progression in children. Clin Exp Optom 2006; 89: 315 21.

18. Jin CC, Pei RX, Du B, et al. Lag of accommodation predicts clinically significant change of spherical equivalents after cycloplegia. Int J Ophthalmol 2021; 14: 1052-8.

19. Hussaindeen JR, Anand M, Sivaraman V, Ramani KK, Allen PM. Variant myopia: A new presentation? Indian J Ophthalmol 2018; 66: 799-805.

20.Ip JM, Saw SM, Rose KA, et al. Role of near work in myopia: findings in a sample of Australian school children. Invest Ophthalmol Vis Sci 2008; 49: 2903-10.

21.Lin Z, Vasudevan B, Jhanji V, et al. Near work, outdoor activity, and their association with refractive error. Optom Vis Sci 2014; 91: 376-82.

22. Walline JJ. Myopia Control: A Review. Eye Contact Lens 2016; 42: 3-8.

23. Anstice NS, Phillips JR. Effect of dual-focus soft contact lens wear on axial myopia progression in children. Ophthalmology 2011; 118: 1152-61.

24. French AN, Morgan IG, Mitchell P, Rose KA. Patterns of myopigenic activities with age, gender and ethnicity in Sydney schoolchildren. Ophthal. Physiol Opt 2013; 33: 318-28.

25. Mutti DO, Mitchell GL, Hayes JR, et al. Accommodative lag before and after the onset of myopia. Invest Ophthalmol Vis Sci 2006; 47: 837-46.

26. Troilo D, Gottlieb MD, Wallman J. Visual deprivation causes myopia in chicks with optic nerve section. Curr Eye Res 1987; 6: 993-9.

27.Tong L, Huang XL, Koh AL, Zhang X, Tan DT, Chua WH. Atropine for the treatment of childhood myopia: effect on myopia progression after cessation of atropine. Ophthalmology 2009; 116: 572-9.

28. Lanca C, Foo LL, Ang M, Tan CS, et al. Rapid Myopic Progression in Childhood Is Associated With Teenage High Myopia. Invest Ophthalmol Vis Sci 2021; 62: 17.

29. Guirao A, Williams DR. A method to predict refractive errors from wave aberration data. Optom Vis Sci 2003; 80:36-42. 